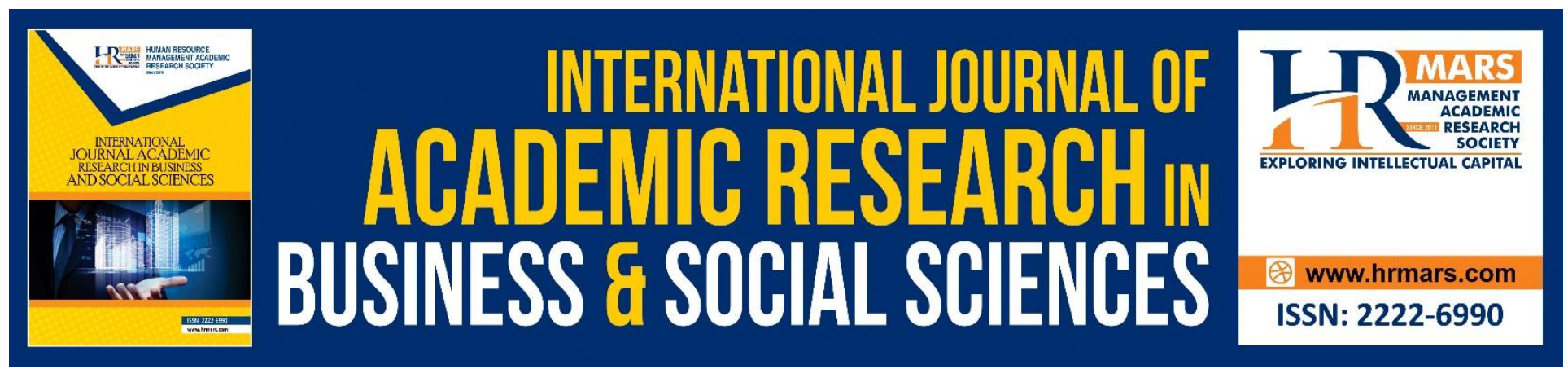

\title{
Attitudes towards Local Anaesthetic Simulator Kit as a Novel Teaching Aid
}

Siti Noorsuriani Maon, Naffisah Mohd Hassan, Tengku Intan Baizura Tengku Jamaluddin

To Link this Article: http://dx.doi.org/10.6007/IJARBSS/v10-i10/7957

DOI:10.6007/IJARBSS/v10-i10/7957

Received: 02 August 2020, Revised: 27 August 2020, Accepted: 17 September 2020

Published Online: 20 October 2020

In-Text Citation: (Maon, Hassan, \& Jamaluddin, 2020)

To Cite this Article: Maon, S. N., Hassan, N. M., \& Jamaluddin, T. I. B. T. (2020). Attitudes towards Local Anaesthetic Simulator Kit as a Novel Teaching Aid. International Journal of Academic Research in Business and Social Sciences. 10(10), 478-487.

Copyright: (C) 2020 The Author(s)

Published by Human Resource Management Academic Research Society (www.hrmars.com)

This article is published under the Creative Commons Attribution (CC BY 4.0) license. Anyone may reproduce, distribute, translate and create derivative works of this article (for both commercial and non-commercial purposes), subject to full attribution to the original publication and authors. The full terms of this license may be seen

at: http://creativecommons.org/licences/by/4.0/legalcode

Vol. 10, No. 10, 2020, Pg. 478 - 487

http://hrmars.com/index.php/pages/detail/IJARBSS

JOURNAL HOMEPAGE

Full Terms \& Conditions of access and use can be found at http://hrmars.com/index.php/pages/detail/publication-ethics 


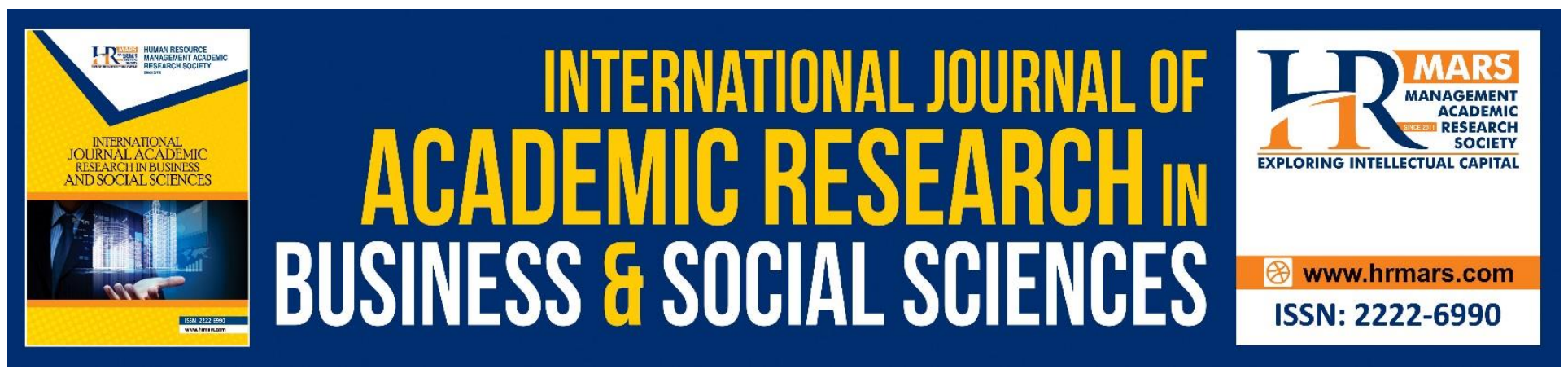

\title{
Attitudes towards Local Anaesthetic Simulator Kit as a Novel Teaching Aid
}

\author{
Siti Noorsuriani Maon ${ }^{1}$, Naffisah Mohd Hassan ${ }^{1}$, Tengku Intan \\ Baizura Tengku Jamaluddin ${ }^{2}$ \\ ${ }^{1}$ Department of International Business and Management Studies, Faculty of Business and \\ Management, Universiti Teknologi MARA (UiTM) Selangor, Malaysia, ${ }^{2}$ Centre of Oral and \\ Maxillofacial Surgery Studies, Faculty of Dentistry, Universiti Teknologi MARA (UiTM) Selangor, \\ Malaysia \\ Email: naffi885@uitm.edu.my
}

\begin{abstract}
Introduction Local anaesthesia is an essential part of dental treatment, and it is formally taught worldwide in the dental curriculum. The inferior alveolar nerve block (IANB) is one of the most common regional anaesthesia techniques used in dental procedures. However, this technique is reported to have the highest failure rate among dental undergraduates, interns and even, dental professionals. Purpose This study primarily aims to present a preliminary assessment of the influence of diffusion of innovation attributes on dental undergraduates' attitudes towards a Novel Local Anaesthesia Simulator Kit (LASK) in performing Inferior Alveolar Nerve Block (IANB). Methodology A cross-sectional survey was conducted using a questionnaire, and it was distributed to selected dental undergraduates. The questionnaire used in this study consisted of items that were adapted from previous studies. A total of 83 completed questionnaires were obtained and considered valid for data analysis. Results All 83 respondents were dental undergraduates from Year 1, involving $69.9 \%$ females and $30.1 \%$ males between the ages of $18-20$. The study's findings reported that relative advantage $(r=.716, p<0.05)$, complexity $(r=.651, p<0.05)$, compatibility $(r=.775, p<0.05)$, observability $(r=.721, p<0.05)$ and trialability $(r=.631, p<0.05)$ were significantly correlated with the attitudes of the dental undergraduates toward the new LASK in performing IANB. Conclusion The findings from this study will help in conducting an actual study in future. Furthermore, these empirical studies will contribute to specific educational significance, especially in the assessment of clinical competence of dental undergraduates at a more microscopic level. Hence, taking the enhancement of dental undergraduates' clinical skills into consideration, we are providing pre-clinical training that improves patients' safety, which is in line with the World Health Organisation's (WHO) Final Report of the Expert Group to the High-Level Commission on Health Employment and Economic Growth.

Keywords: Attitudes, Clinical Simulation, Dental Education, Innovations, Inferior Alveolar Nerve Block, Local Anaesthesia Simulator Kit (LASK).
\end{abstract}


INTERNATIONAL JOURNAL OF ACADEMIC RESEARCH IN BUSINESS AND SOCIAL SCIENCES Vol. 10, No. 10, 2020, E-ISSN: 2222-6990 @ 2020 HRMARS

\section{Background}

Local anaesthesia is an essential part of dental treatment, and it has been an integral part of the worldwide dental curriculum since the 1940s. This was when lignocaine was introduced as the safest anaesthesia medium for dental anaesthesia. Previously, dental anaesthesia was performed by Horace Wells in 1844. The inferior alveolar nerve block (IANB) is one of the most common regional anaesthesia techniques used in dental procedures. However, this technique is reported to have the highest failure rates among dental undergraduates, interns and even, dental professionals. Thus, it is imperative for dental undergraduates to have proper practical training to reduce mistakes and ensure that they master the local anaesthesia administration skills prior to treating patients in their clinical years. In response to this issue, there is a need to conduct a research focuses on development of an innovative local anaesthesia simulator kit (LASK) as a new andragogy in pre-clinical training in performing an IANB.

Conventional and widely used pre-clinical teaching methods in dental schools worldwide are via the skull (bone) or dental models. Despite being instructed through simulation training, most students feel ill-confident and that they are insufficiently prepared for their first injection on a human-being. In response to this, an innovative Local Anaesthesia Simulator Kit (LASK) has been developed and introduced as a new andragogy in pre-clinical training in performing an IANB. LASK is developed using the integration of 3D printing technology and the Internet of Things (IoT) concept. The main aspect of LASK is to provide a simulation environment for dental undergraduates to practise and to monitor the practice of performing IANB in a simulated environment. It is concurrently providing real-time data accessibility (assessment records) for both parties, i.e. dental undergraduates, and dental academicians. The prototype of LASK was found able to provide realtime data feedback and display the results on the user interface (Zainudin et al., 2019). Furthermore, self-reflection of any improvements that could be made prior to real-life administration of IANB to patients is available via training on the LASK. Therefore, this preliminary study is mainly to examine students' attitudes on the intention to use a novel Local Anaesthesia Simulator Kit in performing inferior alveolar nerve block using Rogers' Innovation theory. This study will contribute to the body of knowledge especially for pre-clinical teaching institutions at worldwide dental schools using effective and efficient technique in performing the inferior alveolar nerve block (IANB) in dental procedures, particularly at undergraduate level.

\section{Literature Review}

The adoption of new clinical behaviour by clinicians and the healthcare system is a consequence of multiple factors. Research on the diffusion or adoption of innovations suggests that a few themes come into the game. This can be fundamentally seen during the Coronavirus pandemic. This research study focuses on the use of Diffusion of Innovation Theory in examining dental undergraduates' attitudes regarding their behavioural intention towards the LASK prototype as a teaching aid for dental undergraduates. There are five main factors that influence the adoption of an innovation, and each of these factors is at play to a different extent in five adopter categories; including 1) Relative Advantage - The degree to which an innovation is seen as better than the idea, programme or product it replaces; 2) Compatibility - How consistent is the innovation in terms of the values, experiences, and needs of potential adopters; 3 ) Complexity - How difficult is it for the innovation to be understood and/or use. 4) Trialability - The extent to which the innovation can be tested or experimented with 
INTERNATIONAL JOURNAL OF ACADEMIC RESEARCH IN BUSINESS AND SOCIAL SCIENCES Vol. 10, No. 10, 2020, E-ISSN: 2222-6990 @ 2020 HRMARS

before a commitment to adopt is made; and 5) Observability - The extent to which the innovation provides tangible results.

Diffusion Theory by Rogers has developed one of the better-known theoretical approaches to the diffusion of innovation (Rogers, 2010). This theoretical framework is helpful when determining the adoption of specific clinical behaviours and when deciding which components will require additional effort if diffusion is to occur. It includes a consideration of various aspects of the innovation (or new technology), style of communication, steps in decision making, and the social context. According to Rogers ${ }^{2}$ there are five elements of a new or substitute clinical behaviour namely relative advantage, compatibility, complexity, trialability and observability. Each element will partly determine whether adoption or diffusion of the new activity will occur.

Rogers defines relative advantage as the degree to which an innovation is perceived as better than the idea it supersedes (Rogers, 2010). Research provides information on the cost-effectiveness and potential benefits to patients as a result of implementing a new clinical activity. However, the objective data may be less important than the clinician's perception of whether the innovation will be advantageous. Decisions about implementing best-evidence practice are driven not only by patient's welfare but also by the interplay between the interests of the clinician and the healthcare system (Cain \& Mittman, 2002). However, if the recommended behaviour increases the status of adopting clinicians and brings in more benefits for individuals or the organisation, the innovation may be readily adopted. These will result in an increment of adoption rate towards innovation.

Compatibility is a measure of the degree to which an innovation is perceived as being compatible with existing values, past experiences, and the needs of potential adopters (Rogers, 2010). To increase the probability of adoption, the innovation must address an issue that clinicians or others perceive to be a problem. Thus, an innovation that is more compatible with one's teaching and learning methods is more likely to be assimilated into an individual's learning environment.

Complexity is a measure of the degree to which an innovation is perceived as difficult to understand and use (Rogers, 2010). A clinical procedure is more likely to be adopted if it is simple and well defined. Hence, the level of difficulties of innovation will determine the diffusion rate for IANB adoption as a teaching aid.

Trialability can be defined as the degree to which the innovation may be modified (Rogers, 2010). The ability to test a potential innovation on a limited basis allows clinicians to explore the implementation of the procedure, its acceptability to users, and the potential outcomes.

Rogers defines observability as the degree to which the results of the innovation are visible to others (Rogers, 2010). Previous studies revealed that the findings from the observation would influence the adoption of innovation rate or level (Colquhoun et al., 2017; Sanson-Fisher, 2004). As one of the major goals of the literature review is to outline the direction of the research and show the development of knowledge, we have developed a conceptual framework of the study to examine the relationship between these dependent and independent variables. 


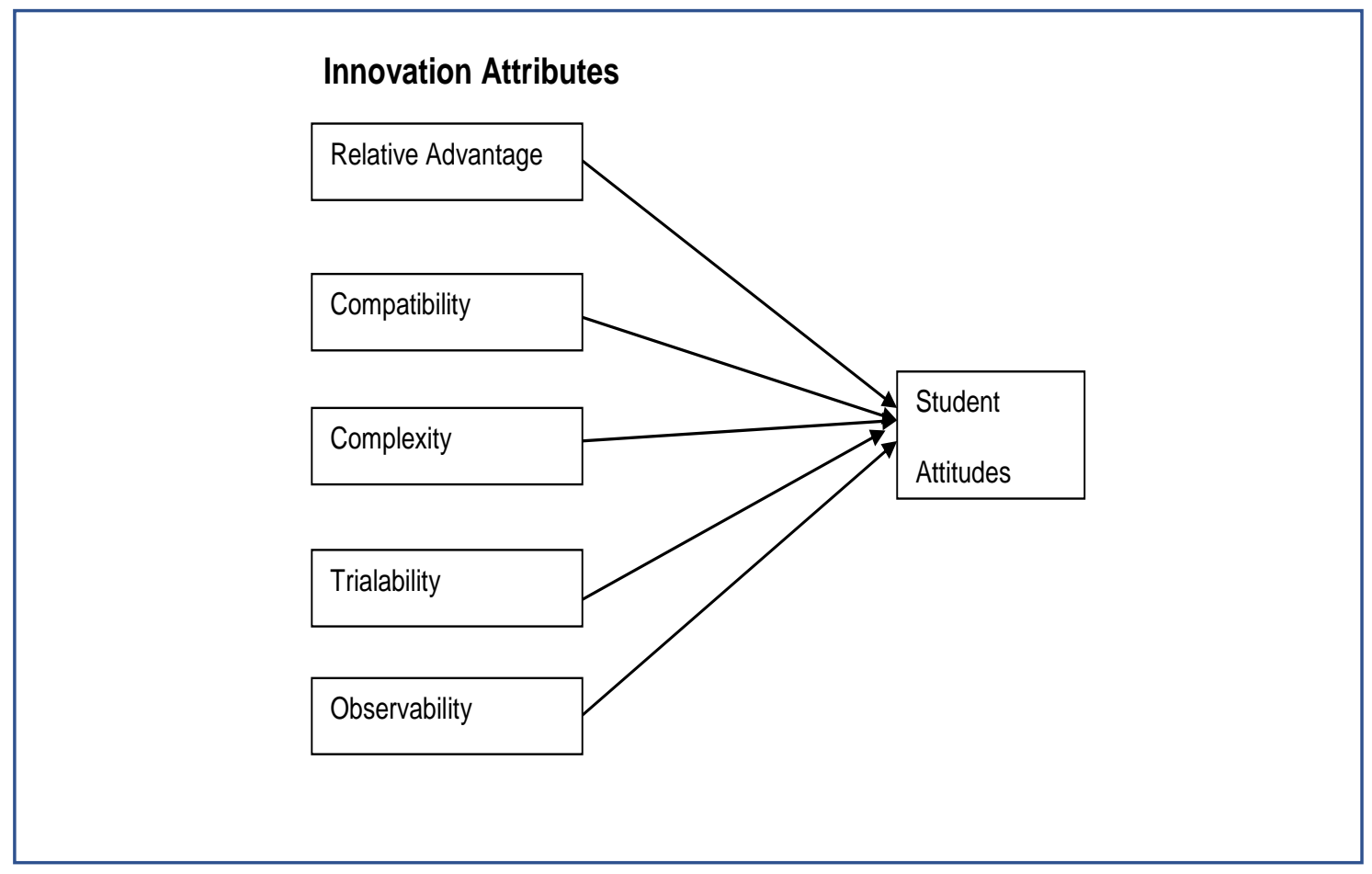

Figure 1. Conceptual Framework of the Study

Therefore, these five characteristics of diffusion of innovation theory play a substantial role in examining the willingness and readiness of individuals in accepting an innovation. This article focussed on answering the main objective of whether dental undergraduates are willing to use LASK as a teaching aid or otherwise? Therefore, based on the conceptual framework in Figure 1, five hypotheses were tested in this study.

- Hypothesis 1: There is a positive relationship between relative advantage and student attitudes on behavioural intention.

- Hypothesis 2: There is a positive relationship between relative compatibility and student attitudes on behavioural intention.

- Hypothesis 3: There is a positive relationship between complexity and student attitudes on behavioural intention.

- Hypothesis 4: There is a positive relationship between trialability and student attitudes on behavioural intention.

- Hypothesis 5: There is a positive relationship between observability and student attitudes on behavioural intention.

By examining these factors, we will be able to foresee the dental undergraduates' attitudes in using LASK as a pre-clinical teaching aid.

\section{Method}

In Malaysia, a dental surgeon is expected to acquire this ability through a formally structured 5-year course at a tertiary institution based on Competency-based Curriculum by the Malaysian Dental Deans' Councils. This curriculum is based on the pre-determined levels in Competencies of New 
INTERNATIONAL JOURNAL OF ACADEMIC RESEARCH IN BUSINESS AND SOCIAL SCIENCES Vol. 10, No. 10, 2020, E-ISSN: 2222-6990 @ 2020 HRMARS

Dental Graduate in Malaysia and approved by the Malaysian Dental Council (2012). The Universiti Teknologi MARA Bachelor in Dental Surgery (BDS) degree is a five-year programme. The Local Anaesthesia module is introduced in the second year. The conventional pre-clinical teaching method requires undergraduates to train on a mandibular (lower jaw) model prior to performing an IANB on their clinical partner in pre-clinical training sessions under the vigilant eyes of the dental educators. A major transition phase between training on a training kit to performing their first injection on a human being may contribute to deficiencies in performing the injection due to shortfalls of the conventional training model as it does not mimic real-life oral environment of a human being. Details of this research's study method are described in the following sections.

\section{Study design and Instrument}

A cross-sectional survey design was employed. This study was carried out at the Faculty of Dentistry, Universiti Teknologi MARA, Sungai Buloh Campus with the study population comprising of first-year dental undergraduates registered in Semester 2/2019.

A 46-item survey questionnaire was used as a method of data collection. This survey question was divided into three sections. Three closed-ended items were used to investigate demographic characteristics of participants in Section A; Section B comprised 36 5-point Likert scale statements (ranging from 1 - strong disagree to 5 - strong agree) on the influence of five constructs of Diffusion of Innovation theory on the dental undergraduates' intention to use LASK. No open-ended questions were included in this survey instrument. Prior to data collection, two local experts reviewed the questionnaire. Their comments to clarify the instrument were integrated to arrive at the final version.

\section{Data analysis and Ethics approval}

All statistical analyses were performed using the IBM SPSS Statistics software (Version 22, IBM SPSS Inc., Chicago, IL). Cronbach's alpha coefficient was used to confirm the internal consistency reliability of the items. The normality of data was checked using skewness and kurtosis values. Table 1 provides details of reliability analysis and data distribution test. Mean values with standard deviation were used to present quantitative data; percentages were provided to summarise the distribution patterns of the categorical data. The correlation between variables was assessed using Pearson correlation with the level of significance set at $P<0.05$.

Table 1

Analysis of Reliability and Data Distribution

\begin{tabular}{llcccc}
\hline No & Construct & $\begin{array}{c}\text { Cronbach's } \\
\text { Alpha }\end{array}$ & Total Item & Skewness & Kurtosis \\
\hline 1 & Relative advantage & 0.930 & 11 & -0.235 & -0.622 \\
2 & Complexity & 0.760 & 5 & 0.477 & 0.633 \\
3 & Compatibility & 0.768 & 6 & 0.562 & -0.464 \\
4 & Observability & 0.846 & 6 & 0.471 & -0.273 \\
5 & Trialability & 0.870 & 5 & 0.069 & -0.534 \\
6 & Attitude & 0.835 & 9 & 0.284 & -0.398 \\
\hline
\end{tabular}


INTERNATIONAL JOURNAL OF ACADEMIC RESEARCH IN BUSINESS AND SOCIAL SCIENCES Vol. 10, No. 10, 2020, E-ISSN: 2222-6990 @ 2020 HRMARS

This research project was approved by Universiti Teknologi MARA Human Research Ethics Committee, Institute of Research Management and Innovation (IRMI) (REC/182/19). Informed consent forms were distributed to the students to indicate their voluntary participation in the project and their right to withdraw from the project at any time without any adverse consequences. Prior to completing the self-administered structured questionnaire, the nature and purpose of the study were explained to the respondents.

\section{Results and Discussion}

Demographic Characteristics

All Year 1 dental undergraduates $(n=83)$ completed the questionnaire, and they comprise $69.9 \%$ females and $30.1 \%$ male undergraduates. The majority of students are between the ages of 18 to 20 $(n=71 ; 85.5 \%)$, and less than $15 \%(n=12)$ are between the ages of 21 to 22 .

In analysing the descriptive data, there was no attempt to add all the results into a composite score, and neutral responses were deleted. Thus, the $\mathrm{N}$-value differs from item to item. A positive attitude will result in a high percentage of positive responses. Hence, less negative items responses will be obtained. Details of the survey's findings are shown in Table 2. Majority of dental undergraduates strongly agree or agree to the intention to continue using this novel teaching aid because of the benefits that LASK offers ( $n=80 ; 96.3 \%)$, ease of use of LASK $(n=74 ; 89.2 \%)$ and help to manage time better $(n=71 ; 85.5 \%)$. Most of the respondents strongly agree and agree to continue using LASK in the future as it is perceived to be appropriate for their profession $(n=78 ; 93.9 \%)$, working style ( $n=72 ; 86.7 \%)$, and having opportunities for the LASK in their profession in the future ( $n=79 ; 95.1 \%)$.

The dental undergraduates also strongly agree and agree that after seeing their classmates using the LASK ( $n=63 ; 75.9 \%$ ) and examining the use of LASK in their study plan, it has made the respondents determine to continue using LASK in the future $(n=71 ; 85.5 \%) .55 .4 \%$ of the respondents disagree and strongly disagree and express the intention to not continue with LASK even when there is difficulty in learning to use the LASK $(n=63)$. For all the survey items, only $6 \%$ of the respondents disagree, namely strongly disagree or disagree to continue to use LASK in future (item C4, C6, C7 and C8). Overall, most dental undergraduates have positive attitudes toward the intention to use the novel teaching aid proposed by LASK. The assessment of attitudes is essential in the undergraduate dental programmes ${ }^{8}$.

\subsubsection{Association of Diffusion of Innovation Attributes and Student's Intention to use}

A Pearson product-moment correlation coefficient test was performed to assess the relationship between the dental undergraduates' attitudes towards LASK and Rogers' theory of innovation attributes including relative advantage, complexity, compatibility, observability and trialability. Cohen's created criterion benchmarks for small ( $r=0.10)$, medium $(r=0.30)$, and large $(r=0.50)$ effect sizes to help interpret the relative size of the correlation magnitudes (Cohen, 2013). 
INTERNATIONAL JOURNAL OF ACADEMIC RESEARCH IN BUSINESS AND SOCIAL SCIENCES

Vol. 10, No. 10, 2020, E-ISSN: 2222-6990 @ 2020 HRMARS

Table 2

Survey findings of students' attitudes of behaviour intention towards LASK $(N=83)$

\begin{tabular}{|c|c|c|c|c|c|c|c|c|}
\hline $\begin{array}{l}\text { Ite } \\
\mathrm{m}\end{array}$ & Statement & SD & D & $A$ & SA & M & SD & $\begin{array}{c}\text { DECISI } \\
\text { ON }\end{array}$ \\
\hline C1 & $\begin{array}{l}\text { The benefits of the LASK will } \\
\text { make me continue to use } \\
\text { them in the future. }\end{array}$ & - & - & $\begin{array}{c}51 \\
(61.4 \\
\%)\end{array}$ & $\begin{array}{c}29 \\
(34.9 \\
\%)\end{array}$ & 4.31 & 0.54 & Positive \\
\hline $\mathrm{C} 2$ & $\begin{array}{l}\text { I intend to continue to use } \\
\text { the LASK because they help } \\
\text { manage my time better. }\end{array}$ & - & - & $\begin{array}{c}49 \\
(59 \%)\end{array}$ & $\begin{array}{c}22 \\
(26.5 \\
\%)\end{array}$ & 4.12 & 0.63 & Positive \\
\hline C3 & $\begin{array}{l}\text { Because the LASK is } \\
\text { appropriate to my } \\
\text { profession, I will use it in } \\
\text { future. }\end{array}$ & - & - & $\begin{array}{c}47 \\
(56.6 \\
\%)\end{array}$ & $\begin{array}{c}31 \\
(37.3 \\
\%)\end{array}$ & 4.31 & 0.58 & Positive \\
\hline C4 & $\begin{array}{l}\text { The LASK usage is } \\
\text { appropriate for my working } \\
\text { style, and I will continue } \\
\text { using it. }\end{array}$ & - & $\begin{array}{c}2 \\
(2.4 \% \\
)\end{array}$ & $\begin{array}{c}48 \\
(57.8 \\
\%)\end{array}$ & $\begin{array}{c}24 \\
(28.9 \\
\%)\end{array}$ & 4.13 & 0.69 & Positive \\
\hline C5 & $\begin{array}{l}\text { The ease of use of the LASK } \\
\text { will make me continue to } \\
\text { use it. }\end{array}$ & - & - & $\begin{array}{c}45 \\
(54.2 \\
\%)\end{array}$ & $\begin{array}{c}29 \\
(35 \%)\end{array}$ & 4.24 & 0.64 & Positive \\
\hline C6 & $\begin{array}{l}\text { The difficulty in learning to } \\
\text { use the LASK will make me } \\
\text { not use it in future. }\end{array}$ & $\begin{array}{c}10 \\
(12 \%)\end{array}$ & $\begin{array}{c}36 \\
(43.4 \\
\%)\end{array}$ & $\begin{array}{c}9 \\
(10.8 \\
\%)\end{array}$ & $\begin{array}{c}5 \\
(6 \%)\end{array}$ & 2.55 & 1.04 & Positive \\
\hline C7 & $\begin{array}{l}\text { Seeing my colleagues use } \\
\text { the LASK will make me } \\
\text { continue to use it. }\end{array}$ & - & $\begin{array}{c}1 \\
(1.2 \% \\
)\end{array}$ & $\begin{array}{c}41 \\
(49.4 \\
\%)\end{array}$ & $\begin{array}{c}22 \\
(26.5 \\
\%)\end{array}$ & 4.01 & 0.74 & Positive \\
\hline C8 & $\begin{array}{l}\text { What I have observed about } \\
\text { the use of the LASK in my } \\
\text { studies will make me keep } \\
\text { using it. }\end{array}$ & - & $\begin{array}{c}1 \\
(1.2 \% \\
)\end{array}$ & $\begin{array}{c}50 \\
(60.2 \\
\%)\end{array}$ & $\begin{array}{c}21 \\
(25.3 \\
\%)\end{array}$ & 4.10 & 0.66 & Positive \\
\hline C9 & $\begin{array}{l}\text { Trying out the opportunities } \\
\text { of using the LASK in my } \\
\text { profession will make me } \\
\text { continue using it in future. }\end{array}$ & - & - & $\begin{array}{c}51 \\
(61.4 \\
\%)\end{array}$ & $\begin{array}{c}28 \\
(33.7 \\
\%)\end{array}$ & 4.29 & 0.55 & Positive \\
\hline
\end{tabular}

Note: Percentages do not equal 100\% because neutral responses were excluded. Abbrev: SD - Strongly Disagree, D-Disagree, A-Agree and SA - Strongly agree

As shown in Table 3, the level of the students' attitudes towards the new LASK teaching aid is positively and significantly correlated with all five constructs of innovation diffusion theory. The five constructs include relative advantage $(r=.716, p<0.05)$, complexity $(r=.651, p<0.05)$, compatibility $(r=.775, p<0.05)$, observability $(r=.721, p<0.05)$ and trialability $(r=.631, p<0.05)$. Overall, the study's findings indicate that the correlation magnitudes are within a large effect. A higher level of innovative attributes is correlated with a higher level of attitudes among dental undergraduates about the new 
INTERNATIONAL JOURNAL OF ACADEMIC RESEARCH IN BUSINESS AND SOCIAL SCIENCES Vol. 10, No. 10, 2020, E-ISSN: 2222-6990 @ 2020 HRMARS

teaching aid LASK. These findings confirm that the perceived attributes of relative advantage, compatibility, complexity, trialability, and observability do influence the adoptions of innovations in learning (Lee et al., 2011).

Table 3

Pearson correlation of innovative attributes with attitude towards LASK

\begin{tabular}{llllllllll}
\hline No & Construct & M & SD & 1 & 2 & 3 & 4 & 5 & 6 \\
\hline 1 & Relative Advantage & 4.321 & .517 & & & & & & \\
2 & Complexity & 3.655 & .513 & $.547^{* *}$ & & & & \\
3 & Compatibility & 4.038 & .476 & $.711^{* *}$ & $.598^{* *}$ & & & \\
4 & Observability & 3.939 & .529 & $.583^{* *}$ & $.509^{* *}$ & $.687^{* *}$ & & \\
5 & Trialability & 4.094 & .556 & $.531^{* *}$ & $.547^{* *}$ & $.669^{* *}$ & $.465^{* *}$ & \\
6 & Attitude & 4.107 & .497 & $.716^{* *}$ & $.651^{* *}$ & $.775^{* *}$ & $.721^{* *}$ & $.631^{* *}$ & \\
\hline$* *$ & Correlation is significant at the 0.01 level (1-tailed). & & & &
\end{tabular}

\section{Conclusion and Recommendation}

Overall, most non-clinical dental undergraduates' students can be considered having positive attitudes towards the new teaching aid of LASK. The level of the students' attitudes towards the new LASK teaching aid is positively and significantly correlated with all five constructs of innovation diffusion theory. Having an effective and efficient technique to perform the inferior alveolar nerve block in dental procedures, particularly at the undergraduate level, is crucial. LASK is currently designed and developed in response to this issue. By introducing LASK to non-clinical dental undergraduates' students will definitely improve their skills and knowledge. Hence, by enhancing the dental undergraduates' clinical skills, we simultaneously provide pre-clinical training that improves patients' safety which is in line with World Health Organisation's (WHO) Final Report of the Expert Group to the High-Level Commission on Health Employment and Economic Growth (WHO, 2016).

\section{Acknowledgement}

The authors would like to acknowledge Universiti Teknologi MARA (UiTM) for funding the research via MITRA Perdana Grant: 600-IRMI/PERDANA 5/3/MITRA (002/2018)-2. We also acknowledge the Faculty of Business and Management and Faculty of Dentistry for supporting the research work.

\section{References}

Cain, M., \& Mittman, R. (2002). Diffusion of Innovation in Health Care. Ihealthreports.

Cohen, J. (2013). Statistical Power Analysis for the Behavioral Sciences. In Statistical Power Analysis for the Behavioral Sciences. https://doi.org/10.4324/9780203771587

Colquhoun, H. L., Squires, J. E., Kolehmainen, N., Fraser, C., \& Grimshaw, J. M. (2017). Methods for designing interventions to change healthcare professionals' behaviour: A systematic review. In Implementation Science. https://doi.org/10.1186/s13012-017-0560-5

Lee, Y. H., Hsieh, Y. C., \& Hsu, C. N. (2011). Adding innovation diffusion theory to the technology acceptance model: Supporting employees' intentions to use e-learning systems. Educational Technology and Society.

Rogers, E. M. (2010). Diffusion of innovations: Simon and Schuster. Computer. https://doi.org/10.1109/2.48 
INTERNATIONAL JOURNAL OF ACADEMIC RESEARCH IN BUSINESS AND SOCIAL SCIENCES Vol. 10, No. 10, 2020, E-ISSN: $2222-6990$ @ 2020 HRMARS

Sanson-Fisher, R. W. (2004). Diffusion of innovation theory for clinical change. Medical Journal of Australia. https://doi.org/10.5694/j.1326-5377.2004.tb05947.x

WHO. (2016). Working for health and growth: investing in the health workforce Growth. In Report of the High-Level Commission on Health Employment and Economic Growth.

Zainudin, S. Z., Ramli, M. H. M., Jamaluddin, T. I. B. T., Wahab, H. A., Husin, A., \& Abdullah, S. A. (2019). The Development of Sensing Architecture for Inferior Alveolar Nerve Block Clinical Simulator Kit. IOP Conference Series: Materials Science and Engineering.

https://doi.org/10.1088/1757-899X/637/1/012005 